DOI: https://doi.org/10.30749/2594-8261.v4n2p428-438

\title{
"EXPERIÊNCIAS DO SERVIR E ADOECER": POTENCIALIDADES DOS ARQUIVOS JUDICIÁRIOS PARA A HISTÓRIA DA SAÚDE E ESCRAVIDÃO
}

\section{“EXPERIENCES OF SERVING AND BECOMING ILL": POTENTIALITIES OF THE JUDICIAL ARCHIVES FOR THE HISTORY OF HEALTH AND SLAVERY}

\section{Barbara Barbosa dos Santos*}

Resumo: A historiografia da escravidão no Brasil apresenta-se em constante movimento para captar cenários ainda turvos da vida das populações escravizadas, estas iniciativas perpassam por iluminar nuances do cotidiano de cativos e libertos no sentido de perceber as sociabilidades, a formação de famílias , o mundo do trabalho escravo, alimentação e formas de resistências nas variadas regiões do país. Neste ínterim se insere as problematizações em torno das condições de saúde entre cativos no Brasil, que na confluência entre a história da escravidão e saúde configura-se como campo fértil, no qual a partir das fontes presentes nos arquivos judiciários, como inventários, processos crimes e denúncias, é possível acessar o comportamento das sociedades escravistas frente ao adoecimento , o impacto das doenças nas relações entre escravizados e senhores, os padrões nosológicos em função das rotinas de trabalho escravo, como também o emprego das práticas de cura sejam as acadêmicas ou alternativas. Sendo assim o artigo que apresentamos busca dar nota das potencialidades dos arquivos judiciários para as investigações sobre as condições de saúde entre cativos no Nordeste.

Palavras-chave: História. Escravidão. Saúde. Judiciário.

Abstract: The historiography of slavery in Brazil presents itself in constant movement to capture still muddy scenarios of the lives of the enslaved populations, these initiatives go through illuminating nuances of the daily life of captives and freedmen in order to perceive sociability, the formation of families, the world of slave labor, food and forms of resistance in the various regions of the country, in the meantime the history of the health of the enslaved is inserted, which at the confluence between the history of slavery and health is configured as a fertile field, in which from the sources present in the judicial archives, such as inventories, criminal cases and denunciations, it is possible to perceive the behavior of slave societies in the face of the illness of the enslaved body, the impact of diseases on the relations between captives and masters, nosological patterns in function of slave labor routines, as well as the use of healing practices, whether academic or alternative. Thus, the article we present seeks to note the potential of the judicial archives for investigations on health conditions among captives in the Northeast.

Keywords: History. Slavery. Health. Judiciary.

\footnotetext{
* Doutoranda em História das Ciências e Saúde pela Fundação Oswaldo Cruz (FIOCRUZ). Mestre em História Social pela Universidade Federal de Sergipe (UFS). Graduada em História pela Universidade Federal de Sergipe (UFS). E-mail: barbara-ceme@hotmail.com.
} 


\section{NAS ENTRELINHAS, O MORRER E ADOECER NA ESCRAVIDÃO}

São ascendentes os estudos voltados para a história das condições de saúde das populações escravizadas no Brasil. O adoecer é fato inerente à vida humana. No entanto, para além de um fenômeno biológico, a doença desencadeia uma série de movimentos nas sociedades, sejam dos sujeitos doentes, dos profissionais ligados a arte de curar ou do Estado, o que a configura também como fenômeno social. Partindo neste viés interpretativo, podemos entrever que, nas sociedades escravagistas dos oitocentos, o adoecimento dos corpos escravizados era carregado de outros significados. Uma vez que o cativo apresentava um valor monetário nas dinâmicas mercadológicas da escravidão imperial, se fazia também espaço de conflito, sobretudo com a proibição do tráfico negreiro na segunda metade do século XIX.

Os estudos do cotidiano das populações escravizadas demandam o olhar aguçado sobre as fontes para percebermos nas entrelinhas a voz, o pensamento e o comportamento destes homens e mulheres que não era considerados cidadãos, e assim, não surgem de maneira explicita nos documentos - ou, quando aparecem, são retratados através do discurso racista e preconceituoso, próprio dos regimes escravistas. Para driblar este quadro, os historiadores que se debruçam sobre a temática analisam a contrapelo a vasta documentação do período: jornais, revistas , literatura e, entre as fontes para o trabalho da história da escravidão no Brasil, destacam-se os documentos produzidos pelo Judiciário: corpos de delito, processoscrime, inventários post mortem, testamentos, cartas de liberdade, entre outros vestígios do acionamento do Judiciário em dramas nos quais uma das partes eram escravizados.

A expectativa de examinar os sujeitos na condição de escravos, na perspectiva da história social, é uma prática que está atrelada à historiografia ocidental. Sobre este movimento de reflexões estrangeiras numa historiografia brasileira, Sidney Chalhoub ponta os trabalhos de Carlo Ginzburg, que se utiliza de um processo eclesiástico para compor sua narrativa, na qual consegue expor os pensamentos e visões de mundo do personagem principal, Menochio, um moleiro. Além deste, o historiador brasileiro ainda aponta um outro trabalho que foi produzido através de um documento produzido pelo Judiciário, o retorno de Martin Guerre. Ambas são obras de grande repercussão na historiografia brasileira, sobre as quais 
inúmeros outros estudos foram esquadrinhados, seguindo as mesmas estratégias de análises.

O que se configura no ponto de vista de Chalhoub é que no bojo das transformações e desenvolvimento da historiografia brasileira, os arquivos judiciários foram incorporados nos estudos, como fontes capazes de iluminar sujeitos que por vezes estavam à margem da sociedade. Em seus próprios trabalhos, percebemos a utilização de inúmeros documentos que o auxiliam a perceber sujeitos escravizados e libertos nas suas trajetórias e experiências a exemplo das obras visões de liberdade e Cidade Febril.

De maneira copiosa, os arquivos judiciários são analisados em função das pesquisas no campo da escravidão, uma vez que, a partir de documentos como inventários post mortem e processos crimes, por exemplo, é possível identificar nuances das famílias escravizadas, da cultura material, do lazer, da resistência e dos mecanismos outros, que os indivíduos escravizados lançavam mão para se desvencilhar das violências ou conseguir seus objetivos dentro do que lhes parecia ser justo.

No que tange às condições de saúde das populações escravizadas, os desafios recaem por perceber as doenças ou a busca da cura nas entrelinhas dos documentos, como também problematizar o impacto das moléstias no universo econômico, como o adoecimento influência as relações entre escravos, senhores e Estado, considerando os casos de negligências e assistência, podendo ir além disto, alcançando assim a atuação médica sobre os corpos escravizados. Estes são alguns dos vieses interpretativos que compõe o horizonte da história da saúde e escravidão que, revisitando uma documentação já utilizada pela historiografia, traz novas informações capazes de reconstruir o cotidiano nas sociedades escravocratas.

Além dos movimentos hospitalares e teses médicas, a história da saúde e escravidão vem se utilizando dos inventários post mortem, uma vez que esta espécie de fonte arrola todos os bens do inventariado. Nos casos de donos de cativos, é anexada a avaliação dos mesmos, como idade e condição física, deixando escapar informações sobre a presença de doenças ou deficiências, o que permite examinar a depender da região como as enfermidades alteram no preço atribuído. Além disso, é possível perceber se os proprietários de escravos executaram gastos financeiros com a saúde de seus cativos ou a contratação de seguros de vida para estes. 
Já os processos-crime e civis nos apresentam uma infinidade de testemunhas que revelam informações sobre o dia a dia de escravos e libertos, que por vezes apontam para a presença de doenças, sofrimentos psíquicos ou deficiência física. Vestígios que o historiador atento às experiências de adoecimento ainda pode captar, a perseguição sobre as práticas de cura empreendidas pelos próprios escravizados, como prisões e condenações sobre os chamados curandeiros por exemplos.

\section{A HISTORIOGRAFIA DA SAÚDE ESCRAVA E OS ARQUIVOS JUDICIÁRIOS}

À primeira vista, considerando as imagens congeladas que se tinha sobre escravização no Brasil, abordar as condições de saúde de cativos invariavelmente recaía sempre em altas taxas de mortalidade e morbidade. Isto é verdade, uma vez que as péssimas condições de vida e trabalho eram um regime comum à camada servil.

Todavia, durante muito tempo este quadro foi generalizado, sem que fosse problematizado com análises mais profundas em torno das experiências de adoecimento, no sentido de perceber que tais vivências eram parte do cotidiano e que portanto mereciam ser examinadas em suas peculiaridades, já que a escravização não ocorre de maneira análoga no país. Mas como adentrar em assunto tão volátil, diante das fontes? Os estudos buscaram responder perguntas como: Afinal de contas, quais eram as doenças que acometiam escravizados em determinada região? Como estas enfermidades mediavam as relações entre escravos e senhores? Como agiam os proprietários frente ao adoecimento de seus cativos? A partir de quais motivadores a classe médica acadêmica passa a produzir estudos em torno do corpo escravizado? É possível traçar o padrão nosológico das populações escravizadas Brasil?

São inúmeras questões que puxam o "novelo de lã" da história da saúde e escravidão, que a cada ano apresenta-se como espaço frutífero para percebermos as particularidades da vida escrava brasileira. Se a utilização dos arquivos judiciários na historiografia brasileira tem influência europeia, a inspiração para as produções sobre a saúde de escravizados no Brasil advém da historiografia estadunidense. Os primeiros estudos que evidenciariam as potencialidades da historicidade das doenças entre escravizados para percepção do cotidiano destas populações ocorreram em torno de fazendas escravistas no Estados Unidos, como os trabalhos escrito por Ulrich 
Phillips, publicado pela primeira vez em 1918 e reeditado na década de 1960, com o título American negro slevery, obra pioneira na historiografia estadunidense. $O$ autor procurou traçar a trajetória da escravização de africanos nas colônias inglesas, atrelada à dinâmica econômica social.

Embora o seu objetivo central não tenha sido a saúde de escravos nos EUA, as condições de saúde são iluminadas em vários capítulos. Além disso, é feito um inventário das doenças que mais acometiam africanos, como disenteria, o escorbuto, varíola e oftalmia. Ainda dar relevo ao comportamento dos senhores através dos diários das fazendas, o autor identificou os cuidados médicos e preventivos para a manutenção da saúde e reprodução de cativos.

Ainda para a historiografia estadunidense que serviu de inspiração nos estudos voltados para a população escravizada brasileira, percebemos o trabalho de William Dosite Postel, que ainda em 1951, elaborou o padrão nosológico das doenças que ceifavam a vida de cativos nas colônias do Norte e do Sul dos EUA. A partir dos livros de óbitos, em seus estudos identificou a carência de vitaminas na alimentação, como também uma possível negligência na higiene e habitação, uma vez que as doenças estavam, frequentemente, associadas ao aparelho digestório (verminoses, diarreias, vômitos, febres) e o respiratório (pneumonias, tisicas, tosses e tifo). O pesquisador foi pioneiro ao sistematizar as doenças e usá-las como pista para se compreender o cotidiano dos cativos munido de dados demográficos. (SANTOS, 2020, p. 27).

Tais produções apontaram as potencialidades das doenças como fios condutores para se chegar ao cotidiano escravo no Brasil. A obra clássica escrita por Mary Karasch $A$ vida dos escravos no Rio de Janeiro é fruto disto, na qual são dedicados capítulos ao assunto. Primeiro, são apresentados detalhes sobre as taxas de mortalidade e morbidade a partir da documentação da Santa Casa do Rio de Janeiro. Depois, numa análise qualitativa, as enfermidades são descritas em função de variantes como idade, sexo e etnia. As moléstias classificadas e associadas às rotinas de trabalho, condições, alimentação, moradia e vestimenta.

Os trabalhos recentes apresentam novas perspectivas, atrelando diferentes categorias de análise sobre variadas regiões. E neste ínterim percebemos a importância das fontes documentais produzidas pelo judiciário, pois com a ausência de registros ligados a hospitais ou enfermarias de fazendas, os inventários, 
testamentos e processos - crimes / Civis dão a possibilidade de acesso às enfermidades presentes no cotidiano escravo.

\section{AS EXPERIÊNCIAS DO SERVIR E ADOECER ESCRITAS NO JUDICIÁRIO BRASILEIRO}

Podemos iluminar através dos trabalhos já produzidos no Brasil, as potencialidades dos arquivos do Judiciário, para uma da história da saúde e escravidão. E neste sentido em nossa historiografia, encontramos a utilização destes documentos judiciários para retratar as mais diversas questões, basilares deste domínio historiográfico, desde a perseguição às terapêuticas alternativas, o impacto das doenças sob o preço dos cativos, a atuação do estado frente a negligência dos senhores, com escravos adoecidos, até aos mecanismos acionados pelos proprietários para o tratamento de doenças em seus cativos, como a contratação de médicos acadêmicos por exemplo.

Que o Judiciário é um espaço fértil para captarmos as questões de saúde da população escravizada, é uma assertiva que se comprova por trabalhos como o apresentado por Rosilene Gomes, com o título "Pai Manoel, o curandeiro africano, e a medicina no Pernambuco imperial" (FARIAS, 2012). Nas ambiências do Recife, no ápice da epidemia do cólera, um escravizado fica conhecido por ter a suposta cura para a doença que na metade do oitocentos ceifava inúmeras vidas. A fama de Manuel pôs em xeque a eficácia da medicina academia, quadro que prova perseguição e por conseguinte sua prisão. As disputas pelas hegemonia quanto a prática de curar foi iluminada pela historiadora Tânia Pimenta Salgado, em seu estudo identificou que mesmo com a institucionalização da medicina, e estruturação de legislações para fiscalização do exercício da curar, os médicos acadêmicos dividiram espaço com terapeutas alternativos (PIMENTA, 2004). Da experiência deste cativo do engenho Guararapes, suas atividades atreladas à prática de curar gerou uma documentação no Judiciário, e apenas por meio dela foi possível conhecer essa peculiaridade das relações entre a escravidão e medicina no nordeste do Império.

Para a região sul, no último quartel do século XIX, o artigo "Já que a desgraça assim queria" um feiticeiro foi sacrificado: curandeirismo, etnicidade e hierarquias sociais (Pelotas - RS, 1879), faz vir a luz o homicídio do Tomás, africano que exercia as funções de curandeiro e feiticeiro em Pelotas, que foi assassinado pelo escravizado 
Antônio que, ao não perceber êxito no trabalho solicitado, achou justo deferir golpes de faca que provocou o objeto do processo-crime, analisado neste estudo. (MOREIRA; AL-ALAM, 2013).

Para além de demonstrar a existência das práticas de cura alternativas empreendidas pelos africanos no Sul, os autores chamam a atenção através dos depoimentos colhidos no processo-crime, para as concepções de equilíbrio presentes nas significações culturais africanas, isto é, o bem-estar, a saúde e a sorte, estavam atreladas a uma relação de equilíbrio com outros elementos místicos e ancestrais. Neste caso, o cativo Antônio recorre ao assassinato de Tomás por entender que assim acharia o equilíbrio e por fim, o seu bem-estar e a superação dos constantes castigos.

Os inventários presentes nos vários arquivos do Judiciário, espalhados pelo Brasil, têm muito a dizer sobre as condições de saúde das populações escravizadas. $\mathrm{Na}$ análise de inventários post mortem entre os anos de 1809-1815, a historiadora Keith Valeria, identificou as principais doenças que acometiam cativos em dez diferentes propriedades produtoras de café no Rio de Janeiro (BARBOSA, 2014). Para além de formatar um padrão nosológico dos escravizados, as moléstias são associadas às condições de trabalho, alimentação e habitação. Nesse sentido, o trabalho ilumina o cotidiano destes sujeitos submetidos à escravização a partir das experiências de adoecimento. Através da documentação judiciária, que também podem nos apontar o impacto das doenças sobre o valor destes cativos que perfaziam as fortunas de seus respectivos senhores para Sergipe, identificamos que pelo menos na segunda metade do século XIX, mesmo com a incidência de doenças, idade avançada ou deficiências, os inventários mostram uma permanência da média de valor sobre cativos. Isto demonstra, entre outras coisas, o apego da sociedade açucareira sergipana à mão de obra escrava (SANTOS, 2020). Ainda em torno da sociedade escravagista sergipana, os inventários post mortem mostram a busca dos donos de cativos pela contratação de médicos para procedimentos e tratamentos em seus escravizados doentes.

Tabela - Lista de gastos médicos com escravos de Manoel Curvelo.

\begin{tabular}{|c|c|c|}
\hline DATA & PROCEDIMENTO & VALOR \\
\hline $8 / 10$ & Uma garrafa de remédio contra oppilação & $5 \$ 000$ \\
\hline $22 / 10$ & Uma garrafa de remédio contra oppilação & $5 \$ 000$ \\
\hline $05 / 12$ & Duas garrafas de remédio contra oppilação & $10 \$ 000$ \\
\hline $7 / 01$ & Duas garrafas de remédio contra oppilação & $10 \$ 000$ \\
\hline
\end{tabular}




\begin{tabular}{|c|c|c|}
\hline $4 / 02$ & Duas garrafas de remédio contra oppilação & $10 \$ 000$ \\
\hline $11 / 02$ & $\begin{array}{l}\text { Trinta e cinco dias de tratamento que teve o escravo Miguel na caza de } \\
\text { morada }\end{array}$ & $70 \$ 000$ \\
\hline 09/03 & Uma visita médica a escrava Alexandrina que padecia do peito & $2 \$ 000$ \\
\hline $27 / 03$ & $\begin{array}{c}\text { Dezessete dias de tratamento que teve a uma escrava na caza da morada a } \\
\text { contar de } 10 \text { o corrente até hoje e a razão de } 2 \$ 000 \text { a diária }\end{array}$ & $34 \$ 000$ \\
\hline $16 / / 04$ & Duas garrafas de remédio contra anemia pedida pelo senhor Curvello & $10 \$ 000$ \\
\hline $25 / 04$ & Uma visita a um escravo padecendo do coração & $2 \$ 000$ \\
\hline $01 / 05$ & Uma visita a mulata escrava Ignacia & $2 \$ 000$ \\
\hline $01 / 05$ & Uma visita a um escravo Simplício & $2 \$ 000$ \\
\hline $08 / 05$ & Duas garrafas de remédio contra anemia pedida pelo finado & $5 \$ 000$ \\
\hline $11 / 05$ & Uma visita ao escravo Simplício & $2 \$ 000$ \\
\hline $12 / 05$ & Uma visita ao escravo Simplício & $2 \$ 000$ \\
\hline $13 / 05$ & Uma incisão de um furúnculo ao mesmo finado & $5 \$ 000$ \\
\hline $16 / 05$ & Uma visita ao escravo Simplício & $2 \$ 000$ \\
\hline $20 / 05$ & Uma visita ao mesmo Curvello com o Dr. Francisco de Bragança & $10 \$ 000$ \\
\hline $21 / 05$ & Três visitas ao mesmo finado sendo duas de dia e uma a noite & $6 \$ 000$ \\
\hline $21 / 05$ & Visita do Dr. Bragança em sua caza & $10 \$ 000$ \\
\hline $22 / 05$ & Três visitas ao mesmo dia sendo duas de dia e uma a noite & $6 \$ 000$ \\
\hline $22 / 05$ & Uma visita com Dr. Bragança & $10 \$ 000$ \\
\hline $23 / 05$ & Três visitas no mesmo dia sendo duas de dia e uma a noite & $6 \$ 000$ \\
\hline $25 / 05$ & Uma visita com Dr. Bragança & $10 \$ 000$ \\
\hline $26 / 05$ & Uma visita com Dr. Bragança & $10 \$ 000$ \\
\hline $02 / 06$ & Uma visita ao escravo Simplicio e a mulata Ignacia & $4 \$ 000$ \\
\hline $02 / 06$ & Importância dos medicamentos fornecidos & $29 \$ 000$ \\
\hline $23 / 08$ & $\begin{array}{l}\text { Trinta e seis dias de tratamento que teve na caza da morada a escrava } \\
\text { Alexandrina a contar desde } 22 \text { de Junho até hoje e a razão de } 26 \text { diarias }\end{array}$ & $64 \$ 000$ \\
\hline $21 / 10$ & Uma garrafa de remédio contra opilação & $5 \$ 000$ \\
\hline
\end{tabular}

Fonte: Autor (2020), adaptado ao inventário de Manuel Curvello Mendonça, 20/04/66, Arquivo Geral do Judiciário do Estado de Sergipe (AGJES), caixa 01-212.

Nesta lista de gastos médicos presente no inventário de um proprietário sergipano, identificamos procedimentos e consultas feitas aos escravizados Simplicio, Alexandrina , Ignazia, Miguel e outros dois que não são identificados pelo nome. Sobre o comportamento de senhores que lançaram mão de mecanismos para a saúde de seus escravos, Keith Valeria no trabalho supracitado também encontrou nos inventários a construção de hospitais para cativos com boticas e enfermarias. Se nos documentos judiciários encontramos senhores envolvidos na preservação da saúde cativa, também podemos perceber mão da justiça buscando responsabilizar os proprietários negligentes. Identificamos em Sergipe uma notificação do presidente de província via judiciário, ao inglês Jorge Marc Carmhi, que possuía uma escrava a qual foi acometida pelo cólera e tratada no hospital de caridade. O documento cobrava do proprietário que ele pagasse a dívida gerada pelo tratamento no ano de $1848^{1}$. A

\footnotetext{
1 Acervo AGJES, LAR/C1OF-Diversos CX 01 - 15/05/1848. Arquivo do judiciário de Sergipe.

LexCult, Rio de Janeiro, ISSN 2594-8261, v.4, n.2, mai./ago. 2020, p.428-438
} 
experiência de Maximiano² é ilustrativa do comportamento do Judiciário frente a debilidade da saúde de cativos em decorrência da violência. Na coluna intitulada noticiário, o Jornal do Aracaju noticiou criticando que no dia 20 de outubro de 1877, na casa de prisão de Aracaju, concluiu-se a pena de açoites, à qual foi condenado o réu escravo Maximiano, por decisão do júri de Socorro em sua sessão de 17 de setembro deste mesmo ano. Maximiano pertencia a Francisco Vieira de Menezes, dono do Engenho Taboca. O cativo residia nesta mesma propriedade com sua esposa Rita, quando no dia três de julho ${ }^{3}$, por motivo ignorado, Maximiano assassinou sua companheira. Após confessar o crime, fora recolhido a cadeia de Aracaju, onde ficou preso dois meses até o seu julgamento.

A crítica do jornal recai sobre a violência aplicada. Para o redator, "o legislador criminal quando adotou o castigo corporal, não quis de certo, como bem considera um distinto criminalista brasileiro que sob a pena de um castigo exalasse o infeliz escravo seu último suspiro. Alguns homens sem consciência e sem coração andam propalando que a sentença não foi cumprida". Ocorre que conforme comemora o redator, o escravo Maximiano teve a felicidade de não sucumbir "à barbara" sentença que the foi imposta. E o Estado interveio a fim de cessar os castigos, uma vez que o cativo não morreu. Para tanto, o Juiz do termo de Aracaju solicitou atestado médico para juntar ao processo na justificativa de cumprimento da sentença. O periódico repercutiu na integra o atestado:

\begin{abstract}
Abaixo transcreve-se os atestados que a requisição do Dr. Juiz municipal do termo, Ihe foi ministrado pelos ilustrados facultativos Dr. Sabino, Dr. Ascendido e Dr. Vasconcelos Francisco Sabino Coelho de Sampaio cirurgião aprovado pela faculdade de medicina da Bahia, doutor em medicina pela mesma faculdade, capitão cirurgião-mor reformado da guarda nacional.

Atesto em virtude de haver -me hoje assim requisitado o illm. Snr. Dr. Juiz municipal do termo desta capital que a 13 corrente achando -me pela manhã casa de prisão com trabalho foi convidado por parte do mesmo juiz para examinar o estado de saúde do preso Maximiano escravo, e emitir meu juízo profissional sobre a possibilidade de sofrer este neste dia o castigo de açoites a que lhe estava condenado, e que há das Ihe estava sendo aplicado, atento o quanto então alegava ao que logo prestando-me declarei ser prudente que se lhe suspendesse o castigo no dia em questão visto haver nele notado muitas contusões aproximadas e de dimensões variadas sobre a face dorsal do tronco, especialmente na parte correspondente ao tórax, em consequência dos açoites recebidos, e dever ter lugar sobre os mesmo tecidos o castigo que tinha ele ainda de sofrer, achando-se estes bastante doloridos e inflamados e mais o pulso lento, pequeno e deprimido, medida esta que aconselhei tendo por fim evitar certas consequências. Por ser verdade o quanto venho de expender, passo o presente para constar.
\end{abstract}

\footnotetext{
2 Acervo AGJES, Jornal do Aracaju 23/10/1877, n. 861.

${ }^{3}$ Acervo AGJES, Jornal do Aracaju 04/07/1877, n. 817.

LexCult, Rio de Janeiro, ISSN 2594-8261, v.4, n.2, mai./ago. 2020, p.428-438
} 


\begin{abstract}
Aracaju 20/10/1877
Nós abaixo firmados doutores em medicina pela faculdade da Bahia, atestamos em fé nosso grau que a convite do illm. Snr. Dr. Mauricio Lobo examinamos nesta data na casa de prisão com trabalho preso Maximiano, escravo que diz ser do Sr. Francisco Vieira de Menezes, e verificamos a existência de crostas sanguíneas resultantes de escoriações e de equimoses numerosas e em diversas direções, de forma alongadas na face posterior do tronco das quais algumas recentes na região escapular esquerda que atribuímos a inflicção de açoites que consta ter o escravo sofrido em cumprimento da sentença

Aracaju 22/10/1877

Dr. Ascendino Ângelo dos Reis

Dr. Manoel Ignacio, de Vaconcelos

Dr. Francisco Sabino Coelho Sampaio4.
\end{abstract}

\title{
4 CONSIDERAÇÕES FINAIS
}

Não conseguimos traçar a trajetória de Maximiano a fim de alcançar quanto tempo ele sobreviveu após a pena de açoites. No entanto, sua experiência nos oferece cenários dos quais podemos perceber a intervenção do Judiciário quanto à preservação da vida e saúde cativa frente à debilidade de sua integridade e o acionamento da medicina.

O que se configura com os exemplos e reflexões que buscamos externar é a importância dos documentos e arquivos do Judiciário para a história da saúde escravidão no Brasil. Estas fontes: processos-crimes; inventários; notificações e corpos de delitos; iluminam nuances imprescindíveis para percebemos detalhes do cotidiano de homens e mulheres submetidos à escravização dos seus corpos.

\section{REFERÊNCIA}

BARBOSA, Keith Valéria de Oliveira. Escravidão, saúde e doenças nas plantations cafeeiras do Vale do Paraíba Fluminense, Cantagalo (1815-1888). 2014. Tese (Doutorado em História das Ciências e da Saúde) - Casa de Oswaldo Cruz, Fundação Oswaldo Cruz, Rio de Janeiro, 2014.

FARIAS, Rosilene Gomes. Pai Manoel, o curandeiro africano, e a medicina no Pernambuco imperial. História, Ciências, Saúde - Manguinhos, Rio de Janeiro, v. 19, supl., p. 215-231, 2012.

MOREIRA, Paulo Roberto Staudt; AL-ALAM, Caiuá Cardoso. "Já que a desgraça assim queria" um feiticeiro foi sacrificado: curandeirismo, etnicidade e hierarquias sociais (Pelotas - RS, 1879). Afro-Ásia, Salvador, n. 47, p. 119-159, 2013.

\footnotetext{
${ }^{4}$ Acervo AGJES, Jornal do Aracaju 04/07/1877, n. 817. 
PIMENTA, Tânia Salgado. Transformações no exercício das artes de curar no Rio de Janeiro durante a primeira metade do Oitocentos. História, Ciências, Saúde Manguinhos, Rio de Janeiro, v. 11, supl., p. 67-92, 2004.

SANTOS, Barbara Barbosa. Moléstias do corpo escravo: doenças e morbidade entre cativos em Sergipe (1865-1888). 2020. Dissertação (Mestrado em História Social) - Universidade Federal de Sergipe, Sergipe, 2020. 